\title{
KONTRIBUSI POWER TUNGKAI DAN KECEPATAN REAKSI TERHADAP TENDANGAN MAE GERI PADA ATLET KARATE PUTRI
}

\author{
Dian Fitra Wanda, Frans Nurseto, Sudirman Husin \\ Fakultas Ilmu Keguruan dan Ilmu Pendidikan \\ Universitas Lampung \\ Email: dianbreww2002@gmail.com
}

\begin{abstract}
This study aims to find out the contribution between power limbs to the results of the mae geri kick on the independent jaya star athlete Tanjung Bintang. The type of research used is descriptive correlational with a sample of 30 female athletes. data collection techniques using tests and measurements. The results of the study and analysis showed that the average results of the measurement of female athlete's limb strength were 2.19, reaction speed of 59.73, the ability to shoot the mae geri 0.267. The results of the study concluded that the limb power contributed to the mae geri kick of $14.60 \%$ in female karate athletes in the independent Jaya star Tanjung Bintang. Reaction Speed gives contribution to mae geri kicks in the amount of $18.7 \%$ in female karate athletes independent jaya star Tanjung Bintang.
\end{abstract}

Keywords: karate, contribution of leg power, speed of reaction, mae geri kicks

\begin{abstract}
ABSTRAK
Penelitian ini bertujuan Untuk mengetahui kontribusi antara power tungkai terhadap hasil tendangan mae geri pada atlet putri bintang jaya mandiri tanjung bintang. Jenis penelitian yang digunakan adalah deskriptif korelasional dengan sampel sebanyak 30 atlet putri. teknik pengumpulan data menggunakan tes dan pengukuran. Hasil penelitian dan analisis menunjukkan rata-rata hasil pengukuran power tungkai atlet putri adalah 2,19, kecepatan reaksi 59,73, kemampuan tendangan mae geri 0,267. Hasil penelitian dapat disimpulkan bahwa power tungkai memberikan kontribusi terhadap tendangan mae geri sebesar $14,60 \%$ pada atlet karate putri bintang jaya mandiri Tanjung Bintang. Kecepatan Reaksi memberikan komtribusi terhadap tendangan mae geri sebesar $18,7 \%$ pada atlet karate putri bintang jaya mandiri Tanjung Bintang.
\end{abstract}

kata kunci: karate, kontribusi power tungkai, kecepatan reaksi, tendangan mae geri

\section{PENDAHULUAN}

Olahraga merupakan salah satu cara untuk mengembangkan dan meningkatkan kesehatan jasmani dan rohani. Olahraga membuat, sistem sirkulasi dan kerja jantung akan meningkat, peningkatan

kekuatan, kelentukan, stamina, kecepatan, dan kondisi fisik lainnya, sedangkan dari segi rohani, tubuh yang bugar tentu akan menumbuhkan rasa percaya diri, berse- 
mangat, dan optimis. tubuh sedang mengalami pertumbuhan fisik, pikiran (mental) harus dibelajarkan dan dikembangkan, hal tersebut akan berdampak pada perkembangan sosial anak. Oleh karena itu, dibutuhkan pendidikan melalui aktivitas fisik tujuannya mencakup semua aspek perkembangan kependidikan.

Pendidikan melalui aktivitas fisik yang dibutuhkan dalam perkembangan kependidikan ini adalah pendidikan jasmani. Pendidikan jasmani dapat diartikan pula sebagai pendidikan melalui gerak insani, ketika tujuan kependidikan dicapai melalui media aktivitas otot-otot besar (gross motorik), memusatkan diri pada gerak fisik dalam permainan, olahraga, dan fungsi dasar tubuh manusia.

UU RI No 3 tahun 2005 Bab II pasal 4 sistem keolahragaan nasional berbunyi keolahragaan nasional bertujuan memelihara dan meningkatkan kesehatan dan kebugaran, prestasi, kualitas manusia, menanamkan nilai moral dan akhlak mulia, sportivitas, disiplin, mempererat dan mem- bina persatuan dan kesatuan bangsa, memperkukuh ketahanan nasional, serta mengangkat harkat, martabat, dan kehormatan bangsa. Dari pernyataan di atas didapatkan bahwa olahraga dapat mengangkat harkat, martabat dan kehormatan bangsa, salah satunya melalui olahraga bela diri, olahraga yang dikenal di masyarakat salah satunya adalah bela diri. Karate merupakan salah cabang seni bela diri yang sangat digemari oleh setiap kalangan umur, tidak kenal usia baik dari usia dini, dewasa, hingga lanjut usia pun menggemari cabang olahraga ini. Di dalam memasyarakatkan olahraga dan mengolahragakan masyarakat, karate merupakan cabang olahraga yang diprioritaskan untuk dibina, maka untuk mendapatkan atlet yang baik, sebaiknya sejak usia dini telah dibina dengan teknik, pola latihan dengan benar.

Karate adalah suatu cara menjalankan hidup yang tujuannya adalah memberikan kemungkinan bagi seseorang agar mampu menyadari daya potensinya, baik secara fisik maupun spiritual. Kalau segi 
spiritual karate diabaikan, segi fisik tidak ada artinya (Sujoto J.B, 1996: 1).

Sejarah olahraga karate berasal dari daratan India yang selanjutnya terus berkembang ke daratan Cina, dari Cina karate kemudian masuk ke Okinawa, Jepang, sekitar 300 tahun yang lalu dan berasimilasi dengan ilmu bela diri di Okinawa, Jepang. Karate sebagai suatu ilmu bela diri (martial arts) dikembangkan lebih intensif lagi di Okinawa sehingga secara resmi dikatakan bahwa karate berasal dari Okinawa, Jepang (Tony, 2009: 59). Semula karate diajarkan secara rahasia, tetapi setelah tahun 1922, Gichin Funakoshi mendemonstrasikannya di Universitas dan pertemuan bela diri di Tokyo.

Karate bukan hanya sekedar untuk belajar bela diri saja akan tetapi telah dijadikan tempat untuk berprestasi setinggi tingginya. Menyadari adanya kepentingan atlet untuk mencapai prestasi tersebut ada beberapa usaha yang dilakukan salah satunya yaitu dengan membuat atau membentuk tempat latihan atau yang sering disebut ranting karate. Ranting karate ini bertujuan untuk membentuk atlet yang mempunyai kemampuan yang baik, baik dari segi teknik, taktik, maupun mental guna mencapai prestasi yang diinginkan.

Power tungkai penting dan diperlukan oleh atlet cabang olahraga yang menuntut unsur kekuatan dan kecepatan gerak. Menurut Harsono (1988: 200), "Power terutama penting untuk cabangcabang olahraga di mana atlet harus mengerahkan tenaga yang eksplosif'. Dewasa ini power telah diakui sebagai komponen kodisi fisik yang memungkinkan atlet untuk mengembangkan kemampuannya guna mencapai tingkat prestasi yang lebih tinggi dalam olahraga yang digelutinya. Karena power ditungkai, seorang atlet renang mampu dengan cepat dan meledak ke luar blok start, pemain basket mampu melompat setinggi-tinggi sebelum melakukan yang cepat dan kuat agar mampu melakukannya berapa kali.

Power tungkai pada tendangan karate selain digunakan untuk melepaskan 
tendangan, kekuatan kaki pada saat menendang untuk menghasilkan power yang besar perlu dikombinasikan dengan koordinasi anggota tubuh yang lain. Kecepatan reaksi juga sangat berpengaruh terhadap hasil tendangan, pada saat akan menendang kecepatan reaksi sangat mendukung hasil tendangan mae geri. Pada saat melakukan tendangan yang ber-power akan secepatnya akan menghasilkan tendangan yang cepat dan kuat menuju lawan dan tendangan yang dihasilkan baik. Reaksi yang cepat saat melakukan tendangan perlu dilatih dan dikembangkan, power tungkai dan kecepatan reaksi dapat dihasilkan dari latihan yang terus menerus.

Pada saat melakukan tindakan yang cepat seorang karateka harus memiliki kemampuan reaksi yang bagus, agar dapat melakukan kecepatan konstan saat melakukan tendangan sehingga dapat menghasilkan tendangan mae geri yang baik. Reaksi pada karate dibutuhkan untuk mencapai kecepatan yang sangat cepat secara menyeluruh, sehingga reaksi akan membantu kecepatan tubuh saat memukul agar dapat mencapai target tendangan yang diinginkan. Tendangan karate tidak hanya reaksi yang dibutuhkan namun ada peranan penting yang dapat menunjang hasil pukulan yaitu power tungkai. Kecepatan reaksi mempunyai peranan yang sangat penting terhadap keberhasilan tendangan mae geri maka harus dilakukan secepat-cepatnya dan kecepatan tetap dipertahankan sampai pada saat akan melakukan tendangan untuk mengenai target. Tendangan ini diperlukan daya tendangan yang besar untuk mendapatkan hasil tendangan yang lebih tepat. Power tungkai di sini diperoleh dari kecepatan kaki yang cepat saat melakukan tendangan.

Tendangan reaksi dan power tungkai mempunyai peranan yang sangat penting terhadap keberhasilan tendangan mae geri yang akan memberikan tenaga yang penting untuk keberhasilan tendangan, karena dengan kekuatan yang besar akan memungkinkan seseorang memiliki tendangan yang lebih kuat sehingga dapat 
menghasilkan prestasi maksimal. Berdasarkan pernyataan di atas dapat diketahui bahwa keberhasilan dalam melakukan tendangan mae geri dipengaruhi oleh beberapa faktor yaitu: tindakan yang cepat dari kecepatan reaksi, serta kekuatan yang besar dari power tungkai.

Mae geri adalah tendangan yang dilakukan dengan bagian cusoku, yaitu pangkal dari seluruh jari-jari kaki yang jari-jarinya dinaikkan atas dan arah serangan dari tendangan ini adalah mata. Oleh karena itu tendangan ini dinamakan mae geri, dengan pengertian mae adalah mata, dan geri artinya tendangan. Cara melakukannya adalah ketika posisi sosuno kamae, atau posisi standard pada jiyo kumite, kaki yang akan menendang diangkat sambil sedikit ditekuk, kemudian dilontarkan secepat-cepatnya ke arah mata lawan hingga lurus, kemudian tarik kembali (Masatoshi Nakayama, 1986: 136).

Berdasarkan hasil pengamatan penulis pada latihan bersama di tempat atlet Forki Bintang Jaya Mandiri Tanjung
Bintang ternyata gerakan yang dilakukan oleh atlet putri belum memaksimalkan komponen pendukung dalam melakukan tendangan mae geri, seperti masih banyak atlet saat disuruh melakukan tendangan atlet lambat dan kurang cepat, dan masih ada siswa yang tendangannya kurang kuat. Hal-hal tersebut secara langsung atau tidak langsung akan mempengaruhi hasil tendangan atlet.

Berdasarkan uraian di atas, maka peneliti memandang perlu untuk mengadakan penelitian yang berjudul "Kontribusi Power Tungkai dan Kecepatan Reaksi terhadap Hasil Tendangan Mae Geri pada Atlet Putri Bintang Jaya Mandiri Tanjung Bintang".

\section{METODE}

Penelitian ini merupakan penelitian korelasional. Penelitian korelasional yaitu penelitian yang dilakukan untuk mengetahui ada tidaknya hubungan antara kedua atau beberapa variabel (Arikunto, 2002: 247). Metode yang digunakan adalah 
survei dengan teknik pengumpulan data menggunakan tes dan pengukuran. Metode survei adalah penyelidikan yang diadakan untuk memperoleh fakta-fakta dari gejalagejala yang ada dan mencari kekurangankekurangan secara faktual (Arikunto, 2006: 56). Populasi dalam penelitian ini Atlet Putri Bintang Jaya Mandiri adalah sebanyak 30 atlet putri.

Dalam penelitian ini terdiri atas dua variabel, yaitu: variabel bebas dan variabel terikat. Variabel bebas adalah variabel yang nilai-nilainya tidak tergantung pada variabel lainnya yang berguna untuk meramalkan dan menerangkan nilai variabel yang disimbolkan dengan (X), adapun variabel bebas dalam penelitian ini yaitu power tungkai $\left(\mathrm{X}_{1}\right)$ kecepatan reaksi $\left(\mathrm{X}_{2}\right)$. Variabel terikat adalah variabel yang nilai-nilainya bergantung pada variabel lainnya dan merupakan variabel yang diterangkan nilainya dan dilambangkan dengan (Y). Dan variabel terikat dalam penelitian ini adalah hasil tendangan.
Penelitian ini menggunakan pendekatan one-shot-model yaitu pendekatan yang menggunakan satu kali pengumpulan data: 1) Power tungkai pengukuran menggunakan back and leg dynamometer, 2) Kecepatan reaksi pengukuran menggunakan Whole Body Reaction, 3) Tendangan mae geri pengukuran menggunakan Software Kinovea.

Data yang perlu dikumpulkan ini menggunakan metode survey dengan teknik tes, pengambilan data dilakukan dengan pemberian tes dan pengukuran melalui metode survey, yaitu peneliti mengamati secara langsung pelaksanaan tes dan pengukuran di lapangan. Instrumen yang digunakan dalam penelitian ini meliputi: 1) Back and Leg Dynamometer, 2) Alat Tulis, dan 3) Formulir Tes.

\section{PELAKSANAAN}

Back and Leg Dynamometer 
Peserta tes berdiri di atas tumpuan back and leg dynamometer. Panjang rantai back and leg dynamometer diatur sedemikian rupa sehingga sesuai dengan posisi badan tegak dan kaki agak ditekuk $30^{\circ}$. Tongkat pegangan digenggam oleh tangan kanan dengan posisi pronasi dan oleh tangan kiri dengan posisi supinasi. Tarik tongkat pegangan ke atas dengan menggunakan otot-otot tungkai, dengan jalan meluruskan kaki. Selama melakukan tarikan, kedua bahu ditarik ke belakang. Tumit tidak boleh diangkat dan kaki tetap lurus. Pencatat skor membaca penunjukkan jarum pada skala saat maksimum tercapai. Ulangi sebanyak dua kali dengan selang waktu satu menit. Skor dicatat dalam satuan $\mathrm{kg}$.

\section{Penilaian}

Skor terbaik dari 2 kali percobaan akan dicatat sebagai skor dalam satuan $\mathrm{kg}$ dengan tingkat ketelitian $0,5 \mathrm{~kg}$.

Tabel 1. Norma penilaian tes otot punggung (Back and Leg Dynamometer)

\begin{tabular}{|c|c|l|}
\hline No & Putra & \multicolumn{1}{c|}{ Norma } \\
\hline 1 & $>259,5$ & Baik Sekali \\
\hline 2 & $187,5-259$ & Baik \\
\hline 3 & $127,5-187$ & Sedang \\
\hline 4 & $84,5-127$ & Kurang \\
\hline 5 & $<84$ & Kurang Sekali \\
\hline
\end{tabular}

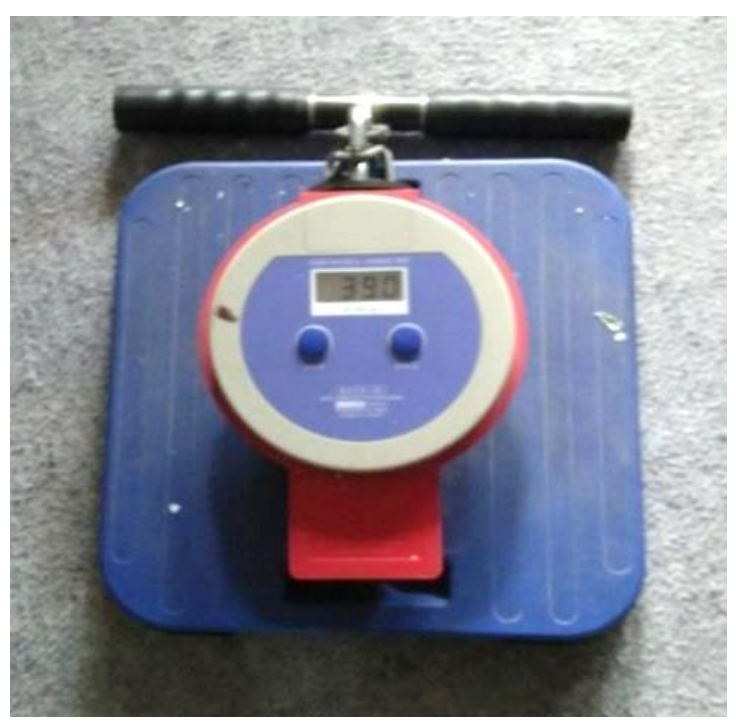

Gambar 1. Back and Leg Dynamometer (Lab Penjas Unila)

\section{Whole Body Reaction}

Whole Body Reaction digunakan untuk mengukur waktu reaksi tangan dan kaki dengan rangsang penglihatan atau pendengaran, alat perlengkapan yang dibutuhkan reaction time meter, dengan ketelitian sampai dengan per 10.000 detik. Alat ini terdiri dari unit operator, unit penjawab dan 4 lampu perangsang dengan warna berbeda, serta bel. 


\section{Alat dan fasilitas}

a. Whole Body Reaction;

b. Alat tulis; dan

c. Formulir tes.

\section{Pelaksanaan}

Alat whole Body Reaction dinyalakan, testee berdiri pada alas tumpu yang tersedia, pandangan ke arah sensor yang akan mengeluarkan cahaya, ketika lampu menyala testi secepatnya melakukan reaksi dengan meninggalkan kedua kaki atau mengeluarkan kedua kaki dari alas tumpu, satuan alat ini adalah detik.

Tabel 2. Norma Whole Body Reaksi Kategori Prestasi (detik)

\begin{tabular}{|r|c|}
\hline \multicolumn{1}{|c|}{ Kategori } & Konversi Nilai \\
\hline Istimewa & $0.001-0.100$ \\
\hline Bagus Sekali & $0.101-0.200$ \\
\hline Bagus & $0.201-0.300$ \\
\hline Cukup/Sedang & $0.301-0.400$ \\
\hline Kurang & $0.401-0.500$ \\
\hline Kurang Sekali & $>0.500$ \\
\hline
\end{tabular}

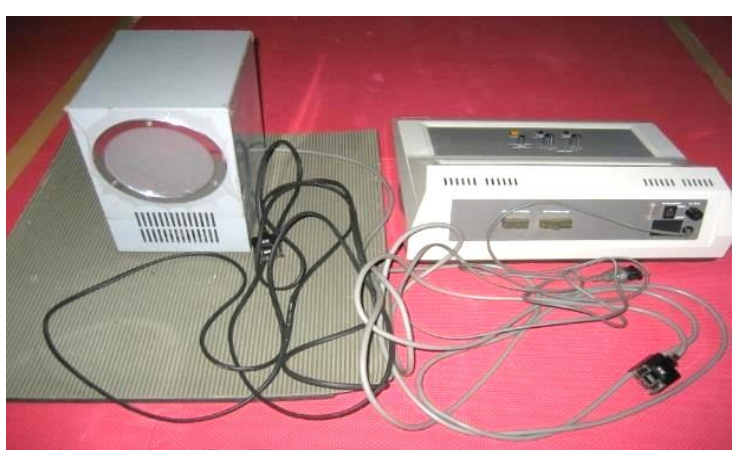

Gambar 2. Whole Body Reaksi

\section{Penilaian}

Angka yang tertera pada display angka ketika orang coba menjawab rangsang menunjukkan waktu reaksinya. Waktu reaksi yang tercepat yang digunakan untuk menilai waktu reaksi testee.

\section{Tendangan Mae Geri}

Metode ini digunakan untuk mengukur hasil tendangan mae geri melakukan tendangan secepatnya selama 10 detik. Sampel melakukan tes sebanyak 2 kali, dilaksanakan di dalam ruangan tertutup, hasil yang diperoleh dalam pelaksanaan tes tersebut adalah merupakan patokan nilai yang dimiliki testee dalam tendangan dan ukuran jumlah tendangan.

\section{Alat dan fasilitas}
a. Samsak;
b. Kamera; 
c. Software kinovea;

d. Pakaian karate (dogi);

e. Blangko pengukuran tend melakukan tendangan mae geri;

f. Alat tulis.

\section{Pelaksanaan}

Kedua testee/karate bediri berhadapan, siap untuk melakukan tendangan, atlet berdiri dengan kaki kiri di depan dan lutut sedikit ditekuk. Setelah diberi aba-aba "ya" atlet langsung melakukan tendangan mae geri menggunakan kaki kanan dengan waktu 10 detik. Tendangan yang dilakukan harus mengenai sasaran, testee dilakukan sebanyak dua kali pengeluaran dan sebagai hasil akhir dilakukan penghitungan dengan alat ukur yang digunakan yaitu software kinovea.

\section{Penilaian}

Testee dapat melakukan tendangan ke lawannya dengan teknik tendangan mae geri selama 10 detik dengan 2 kali pengulangan, nilai terbaik yang diambil.
Tabel 3. Norma Tes Penilaian Tendangan Samsak

\begin{tabular}{|c|c|l|}
\hline No & Putri & \multicolumn{1}{|c|}{ Norma } \\
\hline 1 & $>15$ & Baik Sekali \\
\hline 2 & $13-14$ & Baik \\
\hline 3 & $11-12$ & Sedang \\
\hline 4 & $9-10$ & Kurang \\
\hline 5 & $<8$ & Kurang Sekali \\
\hline
\end{tabular}

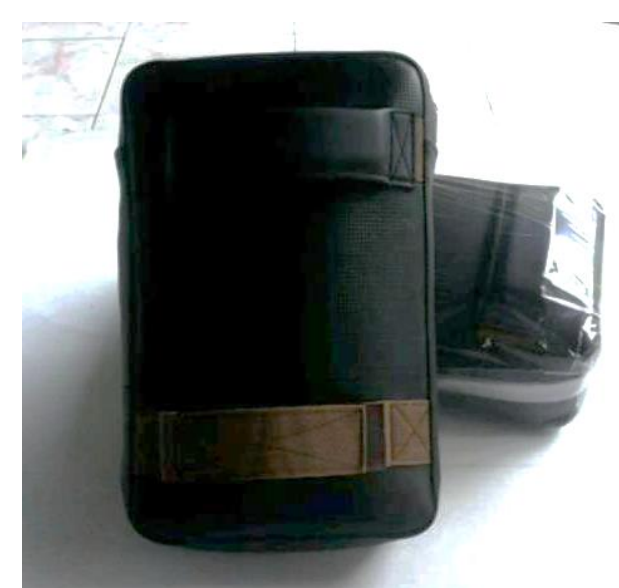

\section{Gambar 3. Samsak}

Data yang dianalisis adalah data variabel bebas yaitu $\left(\mathrm{X}_{1}\right)$ power tungkai $\left(\mathrm{X}_{2}\right)$ kecepatan reaksi, dan variabel terikat (Y) hasil tendangan, $\mathrm{X}_{1}$ terhadap $\mathrm{Y}, \mathrm{X}_{2}$ terhadap Y. Karena sampel penelitian atlet yang diteliti hanya berjumlah 30 atlet maka perhitungan statistik dihitung dengan cara manual.

Teknik analisis yang digunakan dalam penelitian ini adalah analisis regresi linier sederhana dilanjutkan dengan men- 
cari kontribusi dari masing-masing prediktor terhadap variabel tidak bebas dalam Arikunto (2010), untuk menguji hipotesis antara $\mathrm{X}_{1}$ dengan $\mathrm{Y}, \mathrm{X}_{2}$ dengan $\mathrm{Y}$, digunakan statistik melalui korelasi product moment dengan rumus sebagai berikut:

$$
r_{x y}=\frac{n \sum x y-\left(\sum x \sum y\right)}{\sqrt{\left.\left\{n \sum x^{2}-\left(\sum x\right)^{2}\right\} n \sum y^{2}-\left(\sum y\right)^{2}\right\}}}
$$

Keterangan:

$\mathrm{r}_{\mathrm{xy}}=$ Koefisien relasi

$\mathrm{n} \quad=$ Jumlah sampel

$\mathrm{X} \quad=$ Skor variabel $\mathrm{X}$

$\mathrm{y} \quad=$ Skor variabel $\mathrm{Y}$

$\Sigma \mathrm{x}=$ Jumlah skor variabel $\mathrm{x}$

$\Sigma \mathrm{y}=$ Jumlah skor variabel y

$\Sigma \mathrm{x}^{2}=$ Jumlah skor variabel $\mathrm{x}^{2}$

$\Sigma y^{2}=$ Jumlah skor variabel $\mathrm{y}^{2}$

Menurut Sugiyono (2010: 230), harga $r$ yang diperoleh dari perhitungan hasil tes dikonsultasikan dengan Tabel $\mathrm{r}$ product moment. Untuk dapat memberikan penafsiran terhadap koefisien korelasi yang ditemukan besar atau kecil, maka dapat berpedoman pada ketentuan yang tertera pada Interprestasi Koefisien Korelasi Nilai r pada tabel 4.

Setelah diketahui besar kecilnya $\mathrm{r}_{\mathrm{xy}}$, maka taraf signifikan dilihat dengan:

$$
t=\frac{r \sqrt{n-2}}{\sqrt{1-r^{2}}}
$$

Tabel 4. Interpretasi Koefisien Korelasi Nilai $r$

\begin{tabular}{|c|l|}
\hline $\begin{array}{c}\text { Interval Koefisien } \\
\text { Kor elasi }\end{array}$ & \multicolumn{1}{|c|}{$\begin{array}{c}\text { Interpretasi } \\
\text { Hubungan }\end{array}$} \\
\hline $0,80-1,00$ & Sangat Kuat \\
\hline $0,60-0,79$ & Kuat \\
\hline $0,40-0,59$ & Cukup Kuat \\
\hline $0,20-0,39$ & Rendah \\
\hline $0,00-0,19$ & Sangat Rendah \\
\hline
\end{tabular}

Kriteria pengujian hipotesis tolak Ho jika $t_{\text {hitung }}>t_{\text {tabel}}$, dan terima Ho jika $\mathrm{t}_{\text {hitung }}<\mathrm{t}_{\text {tabel. }}$. Untuk dk distribusi $\mathrm{t}$ diambil n-2 dengan $\alpha=0,05$. Dan untuk mencari besarnya sumbangan (kontribusi) antara variabel $\mathrm{X}$ dan variabel $\mathrm{Y}$ maka menggunakan rumus Koefisien Determinasi:

$$
K P=r^{2} \times 100 \%
$$

Keterangan:

$\mathrm{KP}=$ Nilai Koefisien Determinasi

$\mathrm{r} \quad=$ Koefisien Korelasi

\section{HASIL DAN PEMBAHASAN}

\section{Hasil}

Data yang dikumpulkan dalam penelitian ini terdiri dari power tungkai, kecepatan reaksi dan hasil tendangan mae geri pada atlet putri Bintang Jaya Mandiri Tanjung Bintang. Data yang diperoleh dari tiap-tiap variabel tersebut kemudian dike- 
lompokkan dan dianalisis dengan statistik, rangkuman deskripsi data secara seperti terlihat pada lampiran. Adapun keseluruhan disajikan dalam tabel 5.

Tabel 5. Deskripsi Data Hasil Tes Power Tungkai dan Kecepatan Reaksi terhadap Tendangan Mae Geri

\begin{tabular}{|c|l|c|c|c|}
\hline \multirow{2}{*}{ No } & \multirow{2}{*}{ Hasil } & \multicolumn{3}{|c|}{ Variabel } \\
\cline { 3 - 5 } & $\begin{array}{c}\text { Power } \\
\text { Tungkai }\end{array}$ & $\begin{array}{c}\text { Kecepatan } \\
\text { Reaksi }\end{array}$ & $\begin{array}{c}\text { Hasil Tendangan } \\
\text { Mae Geri }\end{array}$ \\
\hline 1 & Sampel & 30 & 30 & 30 \\
\hline 2 & Mean & 2,19 & 59,73 & 0,267 \\
\hline 3 & SD & 0,047 & 16,67 & 0,06 \\
\hline 4 & Max & 0,425 & 100 & 0,36 \\
\hline 5 & Min & 0,232 & 30 & 0,16 \\
\hline
\end{tabular}

\section{Power Tungkai}

Deskripsi data dari pengukuran power tungkai atlet putri Bintang Jaya Mandiri Tanjung Bintang dapat dilihat pada diagram batang hasil power tungkai (gambar 4).

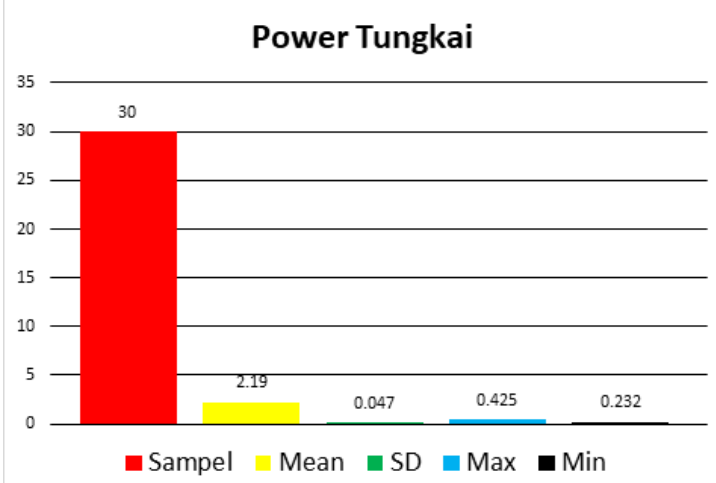

Gambar 4. Diagram Batang Hasil Power Tungkai
Hasil pengukuran power tungkai dengan jumlah sampel 30 orang, menunjukkan bahwa rata-rata power otot tungkai atlet putri Bintang Jaya Mandiri Tanjung Bintang adalah 2,19, standar deviasi 0,047, skor minimum 0,232 dan skor maximum 0,425 .

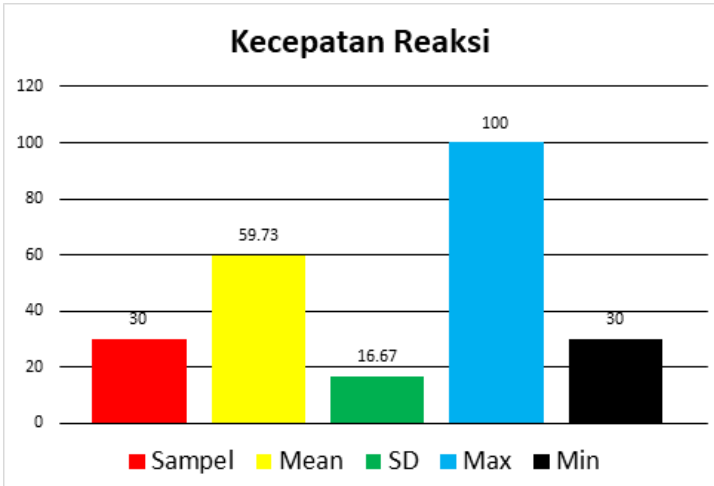

Gambar 5. Diagram Batang Hasil Kecepatan Reaksi 


\section{Kecepatan Reaksi}

Deskripsi data dari pengukuran kecepatan reaksi atlet putri Bintang Jaya Mandiri Tanjung Bintang dapat dilihat pada diagram batang hasil kecepatan reaksi (gambar 5).

Hasil pengukuran kecepatan reaksi dengan jumlah sampel 30 orang, menunjukkan bahwa rata-rata kecepatan reaksi atlet putri Bintang Jaya Mandiri Tanjung Bintang adalah 59,73, standar deviasi 16,67 , skor minimum 30 dan skor maximum 100.

\section{Hasil Tendangan Mae Gery}

Deskripsi data dari tes hasil tendangan mae geri pada atlet putri Bintang Jaya Mandiri Tanjung Bintang dapat dilihat pada diagram batang hasil tendangan mae geri (gambar 6).

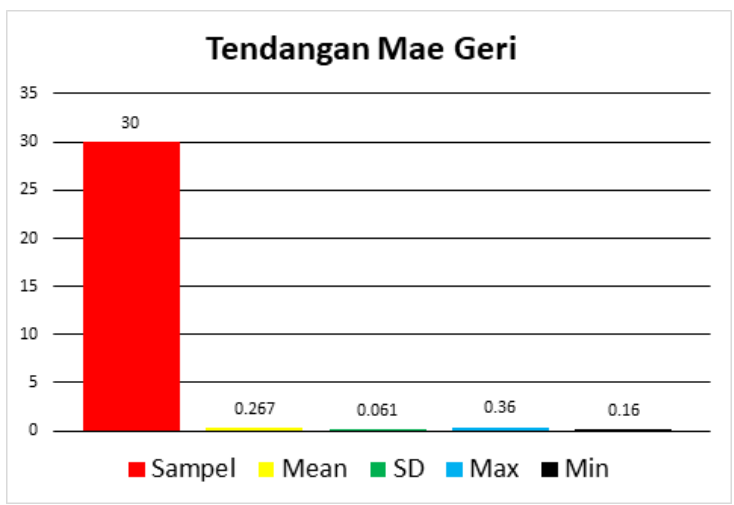

Gambar 6. Diagram Batang Hasil Tendangan Mae Geri
Hasil kemampuan tendangan mae geri pada atlet putri Bintang Jaya Mandiri Tanjung Bintang dengan jumlah sampel 30 orang, menunjukkan bahwa rata-rata atlet putri Bintang Jaya Mandiri Tanjung Bintang adalah 0,267, standar deviasi 0,061 , skor minimum 0,16, dan skor maximum 0,36 .

\section{Analisis Data}

Hipotesis yang diajukan dalam penelitian ini perlu diuji dan dibuktikan melalui data empiris yang diperoleh di lapangan melalui tes dan pengukuran terhadap variabel yang diteliti, selanjutnya data tersebut akan diolah secara statistik. Pengujian hipotesis tersebut maka dilakukan uji korelasi power tungkai dan kecepatan reaksi terhadap tendangan mae geri pada atlet putri Bintang Jaya Mandiri Tanjung Bintang dengan menggunakan statistic korelasi product moment.

\author{
1. Koefisien Korelasi Product Moment \\ Power Tungkai ( $\left.\mathrm{X}_{1}\right)$ dengan Ten- \\ dangan Mae Geri pada Atlet Putri
}


Bintang Jaya Mandiri Tanjung

Bintang (Y).

Data power tungkai diperoleh melalui pengukuran dengan back and leg dynamometer. Keeratan kontribusi power tungkai terhadap tendangan mae geri pada atlet putri Bintang Jaya Mandiri Tanjung Bintang dapat diketahui dengan dilakukan analisis korelasi product moment. Rangkuman hasil analisis data dapat dilihat pada tabel 6 .

Berdasarkan tabel 6 dapat diketahui bahwa: Power otot tungkai memiliki koefisien korelasi product moment 0,382 dengan $\mathrm{r}$ tabel 0,361 dan hasilnya signifikan. Besarnya kontri- busi antara power otot tungkai dengan hasil tendangan mae geri dapat ditentukan dengan koefisien determinasi $\mathrm{r}^{2}$ x $100 \%$, jadi diketahui besarnya kontribusi adalah $14,60 \%$.

\section{Koefisien Korelasi Product Moment} Kecepatan Reaksi (X2) dengan Hasil Tendangan Mae Geri (Y)

Data kecepatan reaksi diperoleh melalui pengukuran dengan whole body reaction. Keeratan kontribusi kecepatan reaksi terhadap tendangan mae geri dapat diketahui dengan dilakukannya analisis korelasi product moment. Rangkuman hasil analisis data dapat dilihat pada tabel 7 .

Tabel 6. Rangkuman Hasil Analisis Product Moment Power Tungkai terhadap Hasil Tendangan Mae Geri pada Atlet Putri Bintang Jaya Mandiri Tanjung Bintang.

\begin{tabular}{|c|c|c|c|l|}
\hline Variabel & $\mathbf{N}$ & $\begin{array}{c}\text { Koefisien } \\
\text { Korelasi }\end{array}$ & rtabel & Kesimpulan \\
\hline $\begin{array}{l}\text { Power tungkai (X } \mathrm{X}_{1} \text { ) - Hasil } \\
\text { tendangan Mae Geri (Y) }\end{array}$ & 30 & 0,382 & 0,361 & Signifikan \\
\hline
\end{tabular}

Tabel 7. Rangkuman Hasil Analisis Product Moment Kecepatan Reaksi terhadap Hasil Tendangan Mae Geri pada Atlet Putri Bintang Jaya Mandiri Tanjung Bintang.

\begin{tabular}{|c|c|c|c|l|}
\hline Variabel & $\mathbf{N}$ & $\begin{array}{c}\text { Koefisien } \\
\text { Korelasi }\end{array}$ & $\mathbf{r}_{\text {tabel }}$ & Kesimpulan \\
\hline $\begin{array}{l}\text { Kecepatan reaksi (X2) - Hasil } \\
\text { tendangan Mae Geri (Y) }\end{array}$ & 30 & 0,432 & 0,361 & Signifikan \\
\hline
\end{tabular}


Berdasarkan tabel 7 dapat diketahui bahwa: Kelincahan memiliki koefisien product moment 0,432 dengan $\mathrm{r}$ tabel 0,361 dan hasilnya signifikan. Besarnya kontribusi antara kecepatan reaksi dengan hasil tendangan mae geri dapat ditentukan dengan koefisien determinasi $\mathrm{r}^{2} \mathrm{x} 100 \%$, jadi diketahui besarnya kontribusi adalah $18,7 \%$.

\section{Uji Hipotesis}

Pengujian hipotesis pada dasarnya merupakan langkah awal untuk menguji persyaratan yang dikemukakan pada rumusan hipotesis bisa diterima atau tidak. Hipotesis yang diajukan bisa diterima jika fakta-fakta empiris atau data yang terkumpul bisa mendukung pernyataan hipotesis. Sebaliknya hipotesis ditolak jika fakta-fakta empiris atau data yang terkumpul tidak mendukung pernyataan hipotesis. Berdasarkan hipotesis yang diajukan dalam penelitian ini yaitu:

\section{Kontribusi Power Tungkai dengan} Tendangan Mae Geri
Berdasarkan hasil analisis product moment pada atlet putri Bintang Jaya Mandiri Tanjung Bintang diperoleh power tungkai memiliki koefisien korelasi product moment 0,382 dengan r tabel 0,361 dan signifikan dengan kriteria korelasi sangat rendah. Sehingga Ho ditolak dan Ha diterima yaitu ada kontribusi yang signifikan antara power tungkai terhadap tendangan mae geri.

Hal ini juga mengandung makna bahwa, apabila seorang atlet karate memiliki nilai power tungkai yang baik maka diikuti hasil tendangan mae geri yang maksimal. Begitu pula sebaliknya apabila seorang atlet karate memiliki nilai power tungkai di bawah normal maka akan diikuti dengan tendangan mae geri yang kurang maksimal.

\section{Kontribusi Kecepatan Reaksi} dengan Tendangan Mae Gery

Berdasarkan hasil analisis product moment pada atlet karate putri 
Bintang Jaya Mandiri Tanjung Bintang diperoleh kecepatan reaksi memiliki koefisien korelasi product moment 0,432 dengan $r$ tabel 0,361 dan signifikan dengan kriteria korelasi sangat rendah. Sehingga Ho ditolak dan Ha diterima yaitu ada kontribusi yang signifikan antara kecepatan reaksi terhadap tendangan mae geri.

Hal ini juga mengandung makna bahwa apabila seorang atlet karate memiliki nilai kecepatan reaksi yang baik maka diikuti dengan hasil tendangan mae geri yang maksimal. Begitu pula sebaliknya apabila seorang atlet karate memiliki nilai kecepatan reaksi di bawah normal maka akan di ikuti dengan tendangan mae geri yang kurang maksimal.

\section{KESIMPULAN DAN SARAN}

\section{Kesimpulan}

Dari hasil penelitian yang telah dilakukan dapat disimpulkan bahwa: 1) Power tungkai memberikan kontribusi terhadap tendangan mae geri sebesar $14,60 \%$ pada atlet karate putri Bintang Jaya Mandiri Tanjung Bintang; 2) Kecepatan Reaksi memberikan komtribusi terhadap tendangan mae geri sebesar 18,7\% pada atlet karate Putri Bintang Jaya Mandiri Tanjung Bintang.

\section{Saran}

Berdasarkan penelitian yang telah dilaksanakan, terdapat beberapa saran yang ingin peneliti simpulkan, adapun saran yang diberikan peneliti, sebagai berikut:

1. Bagi atlet karate putri Bintang Jaya Mandiri Tanjung Bintang agar terus berlatih tentang tendangan mae geri, sehingga saat dipertandingan bisa dimaksimalkan.

2. Bagi peneliti lain yang berminat meneliti kembali permasalahan ini, disarankan agar penelitian ini tidak hanya dijadikan beban pembanding tapi juga penelitian ini dapat ditindaklanjuti dan disarankan untuk menambahkan varia- 
bel lain di antaranya yaitu koordinasi

tendangan dan kepercayaan diri.

3. Bagi program studi penjaskes, diharapkan penelitian ini dapat dijadikan sebagai salah satu acuan dalam program dan pembelajaran untuk meningkatkan kualitas pendidikan maupun calon tenaga pendidik, khususnya di bidang olahraga.

\section{DAFTAR PUSTAKA}

Achmad, Nakayama, M., \& Sabbath Muchsin. (1980). Best karate comprehensive. Cetakan Pertama. New York: Kodansha America, Inc.

Arikunto, S. (2002). Prosedur penelitian: suatu pendekatan praktek. Jakarta: Rineka Cipta.

$\begin{array}{llr}\quad(2006) . & \text { Metode penelitian: } \\ \text { prosedur } & \text { penelitian } & \text { suatu } \\ \text { pendekatan praktik. } & \text { Jakarta: } \\ \text { Rineka Cipta. } & \end{array}$

Bompa, Tudor O. (1990). Theory and methodology of training. Iowa: Kendal/Hunt Publishing.

Eri, Pratikayo. (2010). Tes Pengukuran dan Evaluasi Olahraga. Semarang: Widya Karya.

Evelyin, C.P. (1993). Anatomi \& fisiology untuk paramedis. Alih Bahasa Sri Yuliani Handoyo. Jakarta: PT. Gramedia.
Hairan. (2014). Bela diri: arti luas dan arti sempit. [Online]. Diakses dari http://pengetahuanbeladiri.blogspot .com/2009/05/bela-diri-arti-luasdanarti-sempit.html

Harsono. (1988). Coaching dan aspekaspek psikologi dalam coaching. Bandung: CV. Tambak Kusuma.

M. Sajoto. (1988). Pembinaan kondisi fisik olahraga. Semarang: Dahara Prize.

Nakayama, M. (1979). Best karate 4. Tokyo: Kodansha International.

(1983). Dynamic karate. Tokyo: Kodansha International.

Pear, B., \& Morgan. (1986). Getting stronger: weight training for men and women. California: Shelter Publications. Inc.

Phang, Victorianus. (2012). Karate-do shotokan kata. Bogor: PT. Gramedia.

Prihastono, Arief. (1995). Pembinaan kondisi fisik karate. Solo: CV. Aneka.

Romadhon. (2017). Pengaruh latihan menggunakan resistance band terhadap power tungkai atlet $u \mathrm{~km}$ taekwondo UNY. Skripsi. Yogyakarta: Universitas Negeri Yogyakarta.

Rogres, Tarigan. (2015). Kontribusi latihan koordinasi mata-kaki dan latihan daya ledak otot tungkai terhadap kemampuan pengembangan variasi latihan tendangan ushiro mawashi geri jodan pada atlet kumite karate. (Skripsi). Lampung: FKIP Penjaskes-Unila. 
Rushall, B.S., \& Pyke, F.S. (1990). Training for Sport and Fitness. Melbourne: The Macmillan Company of Australia Ltd.

Simatupang, Janter Ignatius. (2015). Kontribusi power tungkai, panjang tungkai dan keseimbangan terhadap kecepatan tendangan mawasi gery. (Skripsi). Lampung: FKIP Penjaskes-Unila.

Sugiyono. (2017). Metode penelitian kuantitatif kualitatif dan $r \& d$. Edisi Revisi. Bandung: Alfabeta. 